\title{
Spring Mass Characteristics of the Fastest Men on Earth
}

\author{
Authors \\ M. J. D. Taylor ${ }^{1}$, R. Beneke ${ }^{2}$ \\ Affiliations \\ Centre for Sports and Exercise Science, University of Essex, Colchester, United Kingdom \\ ${ }^{2}$ Department of Medicine, Training and Health, Philipps-Universität Marburg, Germany
}

\author{
Key words \\ - sprinting \\ - biomechanics \\ - stiffness \\ athletics \\ - Usain Bolt
}

accepted after revision

February 04, 2012

Bibliography

DOI http://dx.doi.org/

10.1055/s-0032-1306283

Published online:

April 17, 2012

Int J Sports Med 2012; 33:

667-670 @ Georg Thieme

Verlag KG Stuttgart · New York

ISSN 0172-4622

\section{Correspondence}

\section{Dr. Matthew JD Taylor, PhD}

Centre for Sports and Exercise Science

University of Essex

Wivenhoe Park

CO4 3SQ Colchester

United Kingdom

Tel.: +44/01206/872 818

Fax: +44/01206/872 592

mtaylor@essex.ac.uk

\section{Abstract \\ $\nabla$}

The spring mass model has widely been used to characterize the whole body during running and sprinting. However the spring mass characteristics of the world's fastest men are still unknown. Thus the aim of this study was to model these characteristics for currently the 3 fastest men on earth (Usain Bolt, Tyson Gay and Asafa Powell). This was done by using data collected during the 2009 World championships in Berlin

\section{Introduction}

$\nabla$

The $100 \mathrm{~m}$ world record, currently held by Usain Bolt (UB), is $9.58 \mathrm{~s}$. UB is clearly a phenomenal athlete and our work has suggested that his stature and his reduced step frequency facilitate his success resulting in an advantage in relative power development and mechanical efficiency compared to his competitors [3]. Furthermore our past work [4] supported the concept $[3,25]$ that the longer steps of UB with longer ground contact times and longer distances travelled during ground contact generated higher impulses resulting in an exceptionally fast winning time. However we do not know what the spring mass characteristics of the world's fastest men are. Leg and vertical stiffness is often cited as increasing as speed increases, but these studies have been at relatively low speeds $\left(\sim 8 \mathrm{~m} \cdot \mathrm{s}^{-1}\right)[1,6,14,21]$ and not the speeds of world class sprinters.

The spring-mass model (SMM) is used to model both the vertical motion of the centre of mass (CoM) during contact and the stiffness of the leg spring. It has widely been used to characterize the whole body during running and sprinting. The calculation of the effective vertical stiffness $\left(K_{\text {vert }}\right)$ is derived from the maximum vertical force and the displacement of the CoM $\left(\Delta y_{c}\right)$. During running the leg sweeps through an angle thus it is not directly over the CoM (as modelled and the modelling method of Morin et al. [21]. Even though Bolt achieved the greatest velocity $\left(12.3 \mathrm{~m} \cdot \mathrm{s}^{-1}\right)$ over the $60-80 \mathrm{~m}$ split compared to his competitors, his estimated vertical stiffness $\left(355.8 \mathrm{kN} . \mathrm{m}^{-1}\right)$ and leg stiffness $\left(21.0 \mathrm{kN} \cdot \mathrm{m}^{-1}\right)$ were significantly lower than his competitors. This reduction in stiffness is a consequence of Bolt's longer contact time (0.091 s) and lower step frequency $(4.49 \mathrm{~Hz})$. Thus Bolt is able to run at a greater velocity but with lower stiffness compared to his competitors. for $\left.\mathrm{K}_{\mathrm{vert}}\right)$ therefore leg stiffness $\left(\mathrm{K}_{\text {leg }}\right)$ is calculated. These variables are usually derived from double integration of force data. However, a method proposed by Morin et al. [21] mathematically models the force curve as a sine-wave using mass, stature, flight $\left(\mathrm{t}_{\mathrm{f}}\right)$ and contact $\left(\mathrm{t}_{\mathrm{c}}\right)$ times, and velocity data. This model has allowed the SMM to be calculated during the $100 \mathrm{~m}$ for novice sprinters $\left(t_{100} 14.21 \mathrm{~s} ; \bar{v} 7.06 \mathrm{~m} \cdot \mathrm{s}^{-1}\right)$, and the $400 \mathrm{~m}$ of 'well trained athletes' ( $\mathrm{t}_{400} 52.67 \mathrm{~s}$ ) whilst running on the track $[15,22]$. An intriguing application of this approach is to use it in elite competitive events where only running speed and step frequency data are available for $20 \mathrm{~m}$ splits. It was therefore the aim of this study to adopt the model of Morin et al. [21] and apply it to the top 3 male sprinters in the $100 \mathrm{~m}$ World Athletics Championship final of 2009. It was hypothesized that even though UB runs at a greater velocity than his fellow competitors his leg and vertical stiffness would be less due to his reduced step frequency [11] and the requirement for increased impulse [4].

\section{Method \\ $\nabla$}

This study was performed in accordance with the ethical standards laid out by the IJSM [12]. The IAAF commissioned a biomechanics project, 
Table 1 Anthropometric and performance data from the 2009 World Championship.

\begin{tabular}{|llll|}
\hline & UB & TG & AP \\
\hline age $(\mathrm{yrs})$ & 24 & 28 & 28 \\
\hline stature $(\mathrm{m})$ & 1.96 & 1.83 & 1.90 \\
\hline body mass $(\mathrm{kg})$ & 95 & 73 & 88 \\
\hline $\mathrm{t}_{100}(\mathrm{~s})$ & 9.58 & 9.71 & 9.84 \\
$\mathrm{~V}_{100}\left(\mathrm{~m} . \mathrm{s}^{-1}\right)$ & 10.44 & 10.30 & 10.16 \\
\hline
\end{tabular}

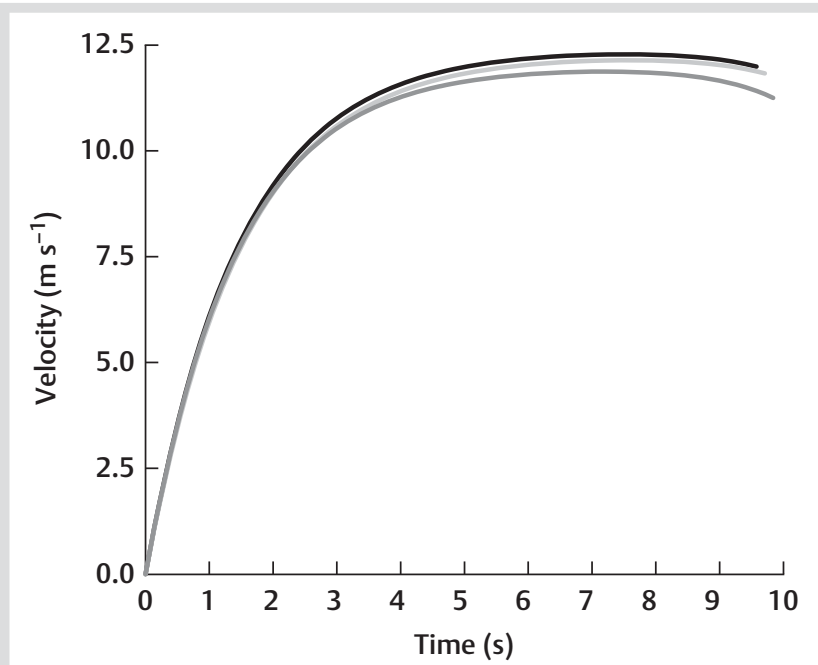

Fig. 1 Velocity profile derived from the bi-exponential model for UB (black line), TG (light grey line) and AP (dark grey line).

undertaken by the German Athletic Federation, which produced individual split times and corresponding step rates for each athlete during the $100 \mathrm{~m}$ final at the 2009 Athletics World Championships in Berlin [12]. We have used this data in previous studies $[3,4]$ to calculate physiological and biomechanical parameters for the first 3 finishers (UB; Tyson Gay, TG; Asafa Powell, AP). We therefore choose to estimate the SMM characteristics for these same athletes. These athletes were chosen for analysis because to date they are the 3 fastest sprinters of all time ( $100 \mathrm{~m}$ personal bests: UB $9.58 \mathrm{~s}$, TG $9.69 \mathrm{~s}$, and AP 9.72s) who between them hold the top 18 all-time $100 \mathrm{~m}$ times [29]. Anthropometric data for all 3 sprinters ( $\bullet$ Table 1 ) were gathered from available reference sources [27]. UB's body mass was adjusted based on a personal statement about his stature and on and off season body mass $[9,28]$.

The velocity profile ( $\bullet$ Fig. 1) of each sprinter was modelled based on the distance covered after individual split times using the integral of a bi-exponential model approximating increase and decrease amplitudes of velocity and corresponding time constants [4]. This resulted in $0.02 \mathrm{~s}$ epochs over the $100 \mathrm{~m}$. The spring mass characteristics (eq. 1-6) were estimated, using the method of Morin et al. [21,22] for the $60-80 \mathrm{~m}$ split only, this was when the sprinters were at their maximal velocity and accelerations/decelerations were minimal. This model [21,22] has been reported to have low bias (0.12-6\%) compared to the reference values from the force plate and high determination coefficients (0.89-0.98). Vertical force (eq.2) was calculated from the body mass of the athlete (in $\mathrm{kg}$ ), the contact $\left(\mathrm{t}_{\mathrm{c}}\right.$, in seconds) and flight $\left(t_{f}\right.$, in seconds) times. Step time $\left(t_{c}+t_{f}\right)$ was calculated from step frequency. Flight time $\left(t_{f}\right)$ data were derived from Weyand et al. [25] which along with step time allowed $t_{c}$ to
Table 2 Estimated SMM characteristics for 60-80 m.

\begin{tabular}{llll} 
Parameter & UB & TG & AP \\
$t_{\mathrm{c}}(\mathrm{s})$ & $0.091 \pm 0.001^{*} \#$ & $0.070 \pm 0.001^{*}$ & $0.080 \pm 0.001$ \\
$t_{\mathrm{f}}(\mathrm{s})$ & $0.132 \pm 0.001^{*} \#$ & $0.132 \pm 0.001^{*}$ & $0.131 \pm 0.001$ \\
$V_{\mathrm{c}}\left(\mathrm{m} \cdot \mathrm{s}^{-1}\right)$ & $12.3 \pm 0.02^{*} \#$ & $12.1 \pm 0.02^{*}$ & $11.9 \pm 0.01$ \\
\hline$F_{\max }(\mathrm{kN})$ & $3.60 \pm 0.001 * \#$ & $3.25 \pm 0.002^{*}$ & $3.59 \pm 0.001$ \\
$K_{\text {vert }}\left(\mathrm{kN} \cdot \mathrm{m}^{-1}\right)$ & $355.8 \pm 0.46^{*} \#$ & $541.8 \pm 0.89^{*}$ & $457.0 \pm 0.47$ \\
$K_{\text {leg }}\left(\mathrm{kN} \cdot \mathrm{m}^{-1}\right)$ & $21.0 \pm 0.05^{*} \#$ & $31.0 \pm 0.05^{*}$ & $28.4 \pm 0.05$ \\
$\Delta y_{\mathrm{c}}(\mathrm{m})$ & $0.01 \pm 0.0001^{*} \#$ & $0.006 \pm 0.0001^{*}$ & $0.008 \pm 0.0001$ \\
\hline$\Delta L(\mathrm{~m})$ & $0.17 \pm 0.0001^{*} \#$ & $0.10 \pm 0.0001^{*}$ & $0.13 \pm 0.0001$ \\
$S F(\mathrm{~Hz})$ & 4.49 & 4.96 & 4.74
\end{tabular}

All data significant to $<\mathrm{p} 0.001$; * Significant difference to AP; \# significant difference to TG. \pm standard deviation

be calculated. Leg stiffness was derived from the maximum vertical force and the change in leg length (eq. 4).

$$
\begin{aligned}
& \mathrm{K}_{\mathrm{vert}}=\mathrm{F}_{\max } \cdot \Delta \mathrm{y}_{\mathrm{c}}{ }^{-1} \\
& F_{\max }=\operatorname{mass} \cdot g \frac{\pi}{2} \cdot\left(\frac{t_{f}}{t_{c}}+1\right)
\end{aligned}
$$

where $\mathrm{g}$ is the gravitational acceleration.

$\Delta \mathrm{y}_{\mathrm{c}}$ (in meters) is the maximal downward displacement of the CoM during contact and was calculated using equation 3.

$$
\begin{aligned}
\Delta y_{c} & =-\frac{F_{\max }}{\operatorname{mass}} \cdot \frac{t_{c}^{2}}{\pi^{2}}+g \cdot \frac{t_{c}^{2}}{8} \\
\mathrm{~K}_{\text {leg }} & =\mathrm{F}_{\max } \cdot \Delta \mathrm{L}^{-1}
\end{aligned}
$$

where $\mathrm{L}$ is leg length (in metres) and is modelled from each athlete's stature according to Winter [26]. Leg length obtained this way has no significant effect on the stiffness values obtained using the method of Morin et al. [21],

$\mathrm{L}=0.53 \mathrm{~h}$

The change in leg length ( $\Delta \mathrm{L}$, in meters) was calculated from

$\Delta L=L-\sqrt{L^{2}-\left(\frac{v_{c} t_{c}}{2}\right)^{2}+\Delta y_{c}}$

\section{Statistical analysis}

$\nabla$

Descriptive statistics (means and standard deviations) and a nonparametric Kruskal-Wallis-Test with a post-hoc Mann-WhitneyTest were used to determine changes in spring mass variables between the 3 sprinters. Statistical significant level was set at $\mathrm{p}<0.05$. Statistical analysis was performed on SPSS ( $v 16.0$ ).

\section{Results}

$\nabla$

The average velocity achieved by UB, TG, and AP over the $60-80 \mathrm{~m}$ splits was $12.19(0.26) \mathrm{m} \cdot \mathrm{s}^{-1}$. Step frequency was markedly less for UB compared to TG and AP ( $\bullet$ Table 2 ). Estimated $F_{\text {max }}$ was significantly greater for UB compared to AP and TG, and AP was significantly greater than TG $\left(\bullet\right.$ Table 2 ). Estimated $\mathrm{K}_{\mathrm{vert}}$ 
and $\mathrm{K}_{\text {leg }}$ for UB were significantly less compared to TG and AP. Estimated $\mathrm{K}_{\mathrm{vert}}$ for UB was $52 \%$ and $28 \%$ less than TG and AP respectively and estimated $K_{\text {leg }}$ was $47 \%$ and $35 \%$ less compared to TG and AP, respectively. TG had the greatest stiffness characteristics of all the sprinters and this was in part due to the significantly shorter $\mathrm{t}_{\mathrm{c}}$ and reduced $\Delta \mathrm{y}_{\mathrm{c}}$ and $\Delta \mathrm{L}$ compared to UB and AP ( $\bullet$ Table 2 ). $\mathrm{t}_{\mathrm{f}}$ was statistically significantly different between all athletes, however this was due to the calculation method of flight time and it is in practical terms not a significant finding.

\section{Discussion}

The spring mass characteristics of world class sprinters, in competition, who run at velocities in the region of $12.19(0.26) \mathrm{m} \cdot \mathrm{s}^{-1}$ have not previously been reported. Morin et al. [21] reported the spring mass characteristics of novice sprinters running at a velocity of $8.24(0.24) \mathrm{m}^{-1} \mathrm{~s}^{-1}$ (during $60-80 \mathrm{~m}$ split), the sprinters

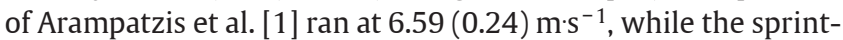
ers of He et al. [14] and Cavagna et al. [8] ran at $6 \mathrm{~m} \cdot \mathrm{s}^{-1}$ and $5 \mathrm{~m} \cdot \mathrm{s}^{-1}$, respectively.

Prior to discussing the results it should be made clear that these data are modelled and are therefore estimates. We acknowledge that there may be limitations in our approach, but the opportunity to take direct measurements in a world championship final to calculate SMM characteristics is, at the moment, unlikely to happen. The sine-wave model of calculating stiffness [21] has been shown to be a valid method of estimating stiffness. However it does have limitations. Namely the model assumes a constant point of force application on the ground during stance phase, when the location actually moves $0.16 \mathrm{~m}$ [17]. The limitations associated with spring-mass models per se are also applicable to the sine-wave model [21].

The sine-wave model requires flight $\left(t_{f}\right)$ and contact time $\left(t_{c}\right)$ which were not directly measured during the $100 \mathrm{~m}$ final. We estimated $t_{f}$ and $t_{c}$ via step frequency, which allows the calculation of step time. $t_{f}$ data were derived from Weyand et al. [25] which along with step time allowed $t_{c}$ be to calculated. Both $t_{f}$ and $t_{c}$ were comparable to those measured via kinematics, accelerometry or on an instrumented treadmill [10,15,22]. Furthermore our data was also comparable to world class sprinters (Ben Johnson $\left(11.76 \mathrm{~m} \cdot \mathrm{s}^{-1}\right) /$ Carl Lewis $\left(11.63 \mathrm{~m} \cdot \mathrm{s}^{-1}\right)$ ) recorded at the 1987 World Athletic championships with $t_{c}$ of $0.082 / 0.085 \mathrm{~s}$ and $\mathrm{a} \mathrm{t}_{\mathrm{f}}$ of $0.122 / 0.138 \mathrm{~s}$ at the $60 \mathrm{~m}$ split for both sprinters [20]. Therefore the calculated $t_{f}$ and $t_{c}$ data can be used in this context to estimate SMM. Lastly, we were unable to take direct measurements of mass, stature and leg length. Therefore we used anthropometric data freely available in the public domain. These data have been used in previous sprinting, and sprinting and anthropometric studies [3,9]. Anthropometrical measures have a 1:1 weighting (or less) on stiffness measures [21]. A percentage change in leg length has virtually no impact on vertical or leg stiffness whereas a $10 \%$ reduction in body mass has a $10 \%$ reduction in stiffness and vice versa [21].

Running velocity is the product of step frequency (SF) and step length (SL). An inverse relationship exists between SF and SL at maximum effort, thus an increase in SF for example will lead to a decrease in SL and vice versa. UB had a longer step length to accompany his slower step frequency whereas TG and AP had shorter step lengths to accompany their faster step frequency [12]. To accommodate the higher step frequencies during running the leg spring becomes stiffer [11]. The size of the sprinter will impact upon these spatial parameters which in turn will impact upon the stiffness characteristics. We only simulated the spring mass characteristics for 3 sprinters with UB perhaps exhibiting an extreme in morphology compared to his competitors and that there may be greater variance in body size among elite sprinters. However, Charles and Bejan stated that world record holders in the $100 \mathrm{~m}$ sprint are becoming taller and heavier [9]. This agreed with Watts et al. [24] who studied not just the world record holders but the top 10 athletes spanning 10 decades of recorded competition. They found that the reciprocal ponderal index (indicating that athletes have become taller and more linear) is a more significant factor of success. Bejan et al. further explored the evolution of height and sprinting speed and suggested that it is the height which the CoM falls from which is indicative of sprinting performance - if the CoM falls from a greater height the more advantageous [5]. The location of the CoM is dependent upon the morphology of the body, thus an athlete with longer limbs and narrower circumferences of body segments (i.e., the shanks) will result in a higher position of the CoM. The results support that UB's tall stature enabled for longer steps with longer ground contact times and longer distances travelled during ground contact [4]. This required lower force and power to generate higher impulses during ground contact under favourable conditions of force generation [3] and biomechanical efficiency [3].

Estimated $\mathrm{F}_{\max }$ was greater than that reported for slower sprinters [i.e., 22] and comparable to sprinters running at $10.37 \mathrm{~m} \cdot \mathrm{s}^{-1}$ [6]. The greater $F_{\max }$ is indicative of sprinting performance faster top speeds are achieved by applying increased vertical forces [25]. Weyand et al. suggested that faster runners had briefer contact times which made greater vertical forces possible [25]. The simulation in this present work however suggests that greater $\mathrm{F}_{\max }$ was achieved for UB who actually had a longer contact time and ran at a faster velocity than his competitors. This present study and others [i.e., 14, 22, and 25] have all focused on the vertical force component. However it should be noted that anterior-posterior forces are also manipulated to improve sprint performance $[18,19]$.

The estimated peak displacement of the leg spring $(\Delta \mathrm{L})$ was comparable to that reported previously using the same model [22]. The maximal downward displacement of the CoM was markedly reduced in these elite sprinters compared to novice sprinters [22] indicating at maximum speed elite sprinters exhibit reduced vertical displacement. This along with the markedly increased $F_{\max }$ (which is comparable $(\sim 3.0 \mathrm{kN}$ ) to sprinters running at $\left.10.37 \mathrm{~m} \cdot \mathrm{s}^{-1}[6]\right)$ resulted in an increase in $\mathrm{K}_{\mathrm{vert}}$ compared to slower sprinters. As speed increases $\mathrm{K}_{\mathrm{vert}}$ has also been shown to increase [10]. The $K_{\text {vert }}$ reported here is $3.8-$ 5.7 times greater than for slower sprinters [22]. These results also show that even though UB achieved the greatest velocity his $\mathrm{K}_{\mathrm{vert}}$ was significantly lower than his competitors. This paradox is partly due to the significantly increased $t_{c}$ for UB compared to TG and AP. Similarly $t_{c}$ along with significantly greater $\Delta \mathrm{L}$ for UB resulted in a significantly lower $\mathrm{K}_{\text {leg }}$ compared to TG and AP.

The data suggest increased $t_{c}$ for UB results in a decreased $K_{v e r t}$ and $\mathrm{K}_{\text {leg }}$ compared to his competitors. This agrees with Morin et al. who manipulated $t_{c}$ at running speed of $3.33 \mathrm{~m} \cdot \mathrm{s}^{-1}$ and showed that $\mathrm{K}_{\mathrm{vert}}$ and $\mathrm{K}_{\text {leg }}$ decreased when $\mathrm{t}_{\mathrm{c}}$ was increased and when $t_{c}$ was decreased $K_{v e r t}$ and $K_{\text {leg }}$ increased [23]. Arampatzis et al. [2] showed that a reduction in $t_{c}$ during drop jumps resulted in an increase in stiffness. Furthermore Arampatzis et al. [2] reported an increase in maximum vertical ground reaction force 
and a greater vertical displacement of the center of mass when $t_{c}$ was increased agreeing with the results for the sprinters in this current study.

As velocity increases from slow $\left(2.0 \mathrm{~m} \cdot \mathrm{s}^{-1}\right)$ to moderate $\left(8.24{\mathrm{~m} \cdot \mathrm{s}^{-1}}^{-1} \mathrm{~K}_{\text {leg }}\right.$ also increases by $60 \%(11.2 \mathrm{kN} / \mathrm{m}-17.0 \mathrm{kN} / \mathrm{m})$ [7]. For the 3 sprinters in this present study, $U B K_{\text {leg }}$ was comparable to sprinters running at slower velocities [15,22] however $\mathrm{K}_{\text {leg }}$ for TG and AP were 1.6 and 1.5 times greater, respectively, compared to slower sprinters reported in the literature [15,22]. The greater vertical and leg stiffness seen for TG and AP may help resist the collapse of the body during contact and enhance force production during push-off, ultimately resulting in increased step frequency [7]. For UB step frequency is less than his competitors and the lower $\mathrm{K}_{\text {leg }}$ and $\mathrm{K}_{\mathrm{vert}}$ and increased $\Delta \mathrm{L}$ and $\Delta \mathrm{y}_{\mathrm{c}}$ suggest greater compliance for UB thereby facilitating the storage and utilization of elastic energy during the stretch shortening cycle [7]. The greater $t_{c}$ and lower step frequency for UB appears to be advantageous as it allows an increase in impulse and distance travelled during contact [4]. The increased $t_{c}$ suggests that UB is able to run at a greater velocity but with lower stiffness compared to his competitors.

\section{Conclusion}

$\nabla$

In this present study the SMM characteristics were estimated for world class athletes whilst in competition. Even though UB achieved the greatest velocity $\left(12.3 \mathrm{~m} \cdot \mathrm{s}^{-1}\right)$ over the $60-80 \mathrm{~m}$ split, compared to his competitors, his $\mathrm{K}_{\mathrm{vert}}$ and $\mathrm{K}_{\text {leg }}$ were significantly lower. This reduction in stiffness is a consequence of the increased contact time and lower step frequency. The opportunity to take direct measurements in a world championship final to calculate SMM characteristics is unlikely to happen; therefore these data provide a unique estimation of the SMM at the elite level of competition.

\section{References}

1 Arampatzis A, Bruggemann G-P, Metzler $V$. The effect of speed on leg stiffness and joint kinetics in human running. J Biomech 1999; 32: 1349-1353

2 Arampatzis A, Schade F, Walsh M, Brüggemann GP. Influence of leg stiffness and its effect on myodynamic jumping performance. J Electromyogr Kinesiol 2001; 11: 355-364

3 Beneke R, Taylor MJD. What gives Bolt the edge - A.V. Hill knew it already! J Biomech 2010; 43: 2241-2243

4 Beneke R, Taylor MJD, Leithäuser RM. The fastest men's $100 \mathrm{~m}$ sprint final - Stature and step rate were cues for success. Med Sci Sport Exer 2011; 43: 688

5 Bejan A, Jones EC, Charles JD. The evolution of speed in athletics: why the fastest runners are black and swimmers white. Int J Design Nature 2010; 5: 1-13
6 Bezodis IN, Kerwin DG, Salo AIT. Lower-limb mechanics during the support phase of maximum-velocity sprint running. Med Sci Sports Exerc 2008; 40: 707-715

7 Brughelli M, Cronin J. Influence of running velocity on vertical, leg and joint stiffness: modelling and recommendations for future research. Sports Med 2008; 38: 647-657

8 Cavagna $G$, Heglund $N$, Willems $P$. Effect of an increase in gravity on the power output and the rebound of the body in human running. J Exp Biol 2005; 208: 2333-2346

9 Charles JD, Bejan A. The evolution of speed, size and shape in modern athletics. J Exp Biol 2009; 212: 2419-2425

10 Dalleau G, Belli A, Bourdin M, Lacour JR. The spring-mass model and the energy cost of treadmill running. Eur J Appl Physiol 1998; 77: 257-263

11 Farley CT, Gonzalez 0. Leg stiffness and stride frequency in human running. J Biomech 1996; 29: 181-186

12 Graubner R, Landmann M, Starke A, Buckwitz R. Biomechanik-Projekt Berlin 2009 http://www.fgs.uni-halle.de/fgs_wm2009.htm

13 Harriss DJ, Atkinson G. Update - ethical standards in sport and exercise science research. Int J Sports Med 2011; 32: 819-821

$14 \mathrm{He}$ J, Kram R, McMahon T. Mechanics of running under simulated low gravity. J Appl Physiol 1991; 71: 863-870

15 Hobara H, Inoue K, Gomi K, Sakamoto M, Muraoka T, Iso S, Kanosue K. Continuous change in spring-mass characteristics during a $400 \mathrm{~m}$ sprint. J Sci Med Sport 2010; 13: 256-261

16 Kunz H, Kaufman DA. Biomechanical analysis of sprinting: decathletes versus champions. Br J Sports Med 1981; 15: 177-181

17 Lee CR, Farley CT. Determinants of the center of mass trajectory in human walking and running. J Exp Biol 1998; 201: 2935-2944

18 Mero A, Komi PV. Force-, EMG-, and elasticity-velocity relationships at submaximal, maximal and supramaximal running speeds in sprinters. Eur J Appl Physiol 1986; 55: 553-556

19 Mero A, Komi PV, Gregor RJ. Biomechanics of sprint running. Sports Med 1992; 13: 376-392

20 Moravec P, Ruzocka J, Susanka P, Dostal E, Kodejs M, Nosek M. The 1987 International Amateur Athletic Federation/IAAF scientific project report: time analysis of the 100 meters event at the II World Championships in athletics. New Studies in Athletics 1988; 3: 61-96

21 Morin JB, Dalleau G, Kyrolainen H, Jeannin T, Belli A. A simple method for measuring stiffness during running. J Appl Biomech 2005; 21: $167-180$

22 Morin JB, Jennin T, Chevallier B, Belli A. Spring-mass model characteristics during sprint running: Correlation with performance and fatigueinduced changes. Int J Sports Med 2006; 27: 158-165

23 Morin JB, Samozino P, Zameziati K, Belli A. Effects of altered stride frequency and contact time on leg-spring behavior in human running. J Biomech 2007; 40: 3341-3348

24 Watts AS, Coleman I, Nevill A. The changing shape characteristics associated with success in world-class sprinters. J Sports Sci 2011 [Epub ahead of print]

25 Weyand $P G$, Sternlight $D B$, Bellizzi MJ, Wright S. Faster top running speeds are achieved with greater ground forces not more rapid lag movements. J Appl Physiol 2000; 89: 1991-1999

26 Winter DA. Biomechanics and Motor Control of Human Movement. $2^{\text {nd }}$ ed. Wiley Inter Science, 1990; 75-102

$27<$ http://www.sports-reference.com/olympics/athletes/>

$28<$ <ttp://bbc.co.uk>, http://news.bbc.co.uk/sport1/hi/athletics/8148280.stm

29 <http://www.iaaf.org>, http://www.iaaf.org/statistics/toplists/inout=0/ age $=\mathrm{n} /$ season $=0 /$ sex $=M /$ all $=\mathrm{y} /$ legal $=\mathrm{A} /$ disc $=100 /$ detail.html

\section{Notice:}

This article was changed according to the following erratum on July 26th, 2012

\section{Erratum}

The article contains an error in the Abstract.

Instead of:

This reduction in stiffness is a consequence of Bolt's longer contact time (0.91 s) and lower step frequency (4.49 Hz).

It should read....

This reduction in stiffness is a consequence of Bolt's longer contact time (0.091 s) and lower step frequency (4.49 Hz). 